\title{
Post-aerobic-exercise autonomic responses in hypertensives - a randomized controlled trial
}

\author{
Juliano Casonatto ${ }^{\circledR}$, Liane Sardi Oliveira ${ }^{\circledR}$, Kamila Grandolfi $₫$ \\ University of Northern Paraná, Londrina, Brazil
}

\begin{abstract}
Background. Heart rate variability (HRV) response to an exercise bout may provide useful insight into autonomic stress reactivity. Considering that cardiovascular responses to a stressor may be predictive of certain diseases, it becomes critical to understand if high blood pressure can influence the autonomic nervous system response to acute exercise. We, therefore, undertook a study to investigate the effect of a single bout of aerobic exercise on autonomic responses in hypertensives.

Material and methods. Twenty hypertensives were randomly assigned to one of the two experimental groups [control (CG) or exercise (EG)]. The exercise session was conducted on a treadmill and consisted of 40 min of running/ /walking at 60-70\% HRreserve. In the control session, the participants remained seated in a quiet room for $40 \mathrm{~min}$. After the exercise/control sessions, the HRV was recorded continuously for 60 min.

Results. The EG presented an increase with a large effect size for LF [1.0 (post-30) and 1.0 (post-60)] and LF/HF [0.8 (post-30) and 1.1 (post-60)]. Additionally, a reduction with a large effect was observed for HF [-1.0 (post-30) and -1.0 (post-60)].

Conclusion. There is a considerable reduction in post-aerobic-exercise parasympathetic activity and an increase in sympathetic activity. Therefore, a single bout of aerobic exercise is not able to quickly improve the cardiac autonomic regulation.
\end{abstract}

Key words: autonomic nervous system; hypertension; exercise; cardiovascular diseases; endurance training

Arterial Hypertens. 2020, vol. 24, no. 2, pages: 74-82

DOI: $10.5603 /$ AH.a2020.0009

\section{Introduction}

Heart rate variability (HRV) reflects beat-to-beat changes in RR intervals, which are related to the ongoing interplay between the parasympathetic and sympathetic arms of the autonomic nervous system [1]. Heart rate variability analysis provides a noninvasive and simple method to assess autonomic func- tion. As such, it has been employed in the most diverse areas of clinical research [2].

Measures of HRV analysis may also offer promising electrical biomarkers for predicting cardiac mortality and would be appropriate to be evaluated in well-designed prognostic studies [3]. Hypertension is a chronic condition that can lead to heart disease, stroke, and other diseases that can result in premature death [4],

\footnotetext{
Address for correspondence: Juliano Casonatto

Universidade Norte do Paraná, Rua Marselha, 591, Jd. Piza, Londrina, PR, Brazil, Zip code: 86041-140, tel: (+55) 43 99984-0790; e-mail: juliano2608@hotmail.com
} 


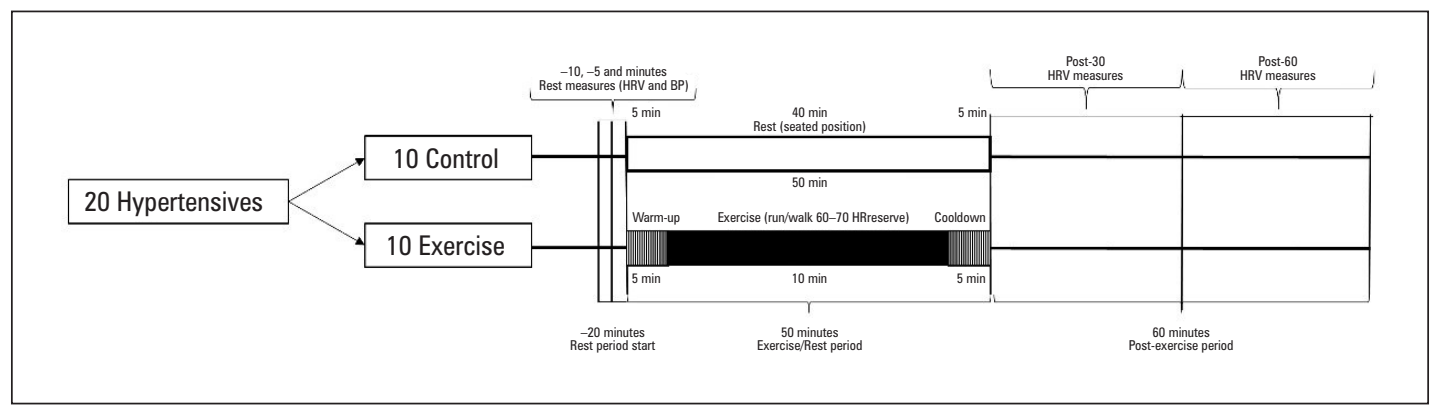

Figure 1. Study design

added to which high HRV is associated with lower morbidity and mortality in patients with hypertension [5].

It is well known that exercise training can increase total HRV in normal older adults [6], athletes [7], and young adults [8]. Additionally, an acute physical exercise session could improve cardiac autonomic modulation in older normotensive, hypertensive treated, and hypertensive untreated subjects [9].

Unlike normotensives, hypertensives present a reduced HRV associated with a predominance of the sympathetic component [10] and other studies have proposed a relationship between HRV and blood pressure levels [9]. This scenario suggests that HRV is likely to be influenced by numerous factors, including the stage of hypertension.

This knowledge could be of clinical relevance since it is known that these patients present impairments in autonomic modulation and physical exercise is widely indicated as part of hypertension management. Furthermore, it is important to establish whether high blood pressure can influence the autonomic nervous system response to acute exercise, as understanding aspects of the exercise response are crucial to perform safe non-pharmacological treatment for hypertension. Thus, the present study was designed to analyze post-aerobic exercise autonomic responses in hypertensive subjects.

\section{Material and methods}

\section{Participants}

After sample size calculation (see statistical analysis session), 20 hypertensive, sedentary (less than 150 minutes per week of moderate physical activities) individuals participated in the study. Volunteers were women or men, adults, without osteoarticular disabilities, and with medical authorization to exercise. Participants were recruited from the university community. The study followed the Declaration of Helsinki and was approved by the Institution Eth- ics Committee (78697617.4.0000.0108). All participants were informed about the methods before giving written informed consent.

\section{Study design}

This was an acute, randomized, parallel-groups clinical trial (Fig. 1) to evaluate the effects of a single bout of aerobic exercise on HRV in hypertensive individuals. The participants were randomly allocated (using a random number table - https://www.random. org/) into two different experimental groups: Control Group (CG) and Exercise Group (EG). Participants were not taking beta-blockers and were asked to refrain from caffeine and alcohol for $24 \mathrm{~h}$ before the experimental session and advised not to make changes to their regular lifestyles other than the assigned interventions. Anthropometric measures were taken before the rest period. The exercise session was conducted on a treadmill and consisted of: a 5 min warm-up (50-65\% HRreserve); 40 min of running/walking at $60-70 \%$ HRreserve; and a $5 \mathrm{~min}$ progressive cool down. In the control session, the participants remained seated in a quiet room for 40 min. After the exercise/control sessions, the HRV was recorded continuously for $60 \mathrm{~min}$. Testing was conducted in the morning at the same time of day 9:00 am $( \pm 1 \mathrm{~h})$ in a quiet, temperature-controlled room $\left(23^{\circ} \mathrm{C} \pm 1^{\circ} \mathrm{C}\right)$.

\section{Anthropometry}

Weight was measured using a digital anthropometric scale (Urano, OS 180A, Canoas, Brazil), with an accuracy of $0.1 \mathrm{~kg}$ and height was measured by a stadiometer with an accuracy of $0.1 \mathrm{~cm}$, in accordance with the procedures described by Gordon et al [11]. The body mass index (BMI) was defined as the body mass $(\mathrm{kg})$ divided by the square of the body height.

\section{Heart rate variability measures}

Heart rate variability was monitored during the rest periods (Fig. 1) using a cardiac monitor (Polar 
RS800CX, Kempele, Finland), previously validated [12]. The participants remained seated in a calm, quiet, and thermoneutral $\left(22^{\circ} \mathrm{C}\right.$ to $\left.24^{\circ} \mathrm{C}\right)$ environment during monitoring. The recorded R-R intervals were transferred to a computer using specific software (Polar Pro-Trainer software, Kempele, Finland). Fast Fourier Transform was applied to quantify the low (LF) and high (HF) frequencies into normalized units, in accordance with the Task Force of the European Society of Cardiology and the North American Society of Pacing and Electrophysiology [1].

The time-domain analysis was obtained through the SDNN (standard deviation of the NN intervals), RMSSD (the square root of the mean of the sum of the squares of differences between adjacent $\mathrm{NN}$ intervals), and pNN50 indices (NN50 count divided by the total number of all $\mathrm{NN}$ intervals). The range interval analysis (Fig. 1) was $10 \mathrm{~min}$ (rest, before exercise), and $30 \mathrm{~min}$ (post-exercise) using Kubios HRV, version 2.2 (Kuopio, Finland).

\section{Blood pressure}

The BP measurements were taken with an oscillometric device (Omron MX3 Plus, Bannockburn, USA) previously validated for clinical measures in adults [13]. The participants remained seated (rest period - Fig. 1) in a calm, quiet, and thermoneutral $\left(22^{\circ} \mathrm{C}\right.$ to $\left.24^{\circ} \mathrm{C}\right)$ environment for $20 \mathrm{~min}$. Blood pressure was measured three times during the rest period (at $10 \mathrm{~min}, 15 \mathrm{~min}$, and $20 \mathrm{~min}$ ). The resting $\mathrm{BP}$ value was considered as the average of these three measurements. The BP measurements were taken according to the American Heart Association recommendations [14].

\section{Statistical analysis}

Assuming a standard deviation of 6 normalized units [15] for the $\mathrm{LF}_{\mathrm{nu}}$, an alpha of 5\%, and a desired statistical power of $95 \%$, to detect a minimum difference of 20 normalized units [15], 6 subjects were required in each group.

Box plots, which provide a spatial representation of the spread of concentration distributions, were used to identify anomalous values among the global population of measurements for each HRV index. In each plot, the box represented the interquartile range and whiskers delineated the region occupied by \pm 1.5 times the interquartile range beyond the box boundaries. For this study, points plotted above or below the whiskers were identified as potential outliers. Histograms were also examined to confirm that these points were located at distribution extremes for each dataset.

The data are reported as mean and standard deviation. A non-parametric Levene's test was used to verify the equality of variances in the samples (homogeneity of variance). Then, an independent samples $\mathrm{t}$-test was used to compare mean characteristics between CG and EG.

To compare the absolute values between experimental groups, firstly, the Mauchly's test of sphericity was applied and the Greenhouse-Geisser correction if necessary. Next, these data were compared with a one-factor repeated measures general linear model (GLM). Fisher multiple comparisons were employed to examine differences between pairs of trials.

Effect size from the paired two-sample t-test was calculated $(d=$ mean $/ S D)$ between "pre" vs. "post30 " and "post-60" for all HRV indices ( $d$-effects: small $\geq 0.2$, medium $\geq 0.50$, large $\geq 0.80$ ).

The pooled Z-score for each period ("pre", "post30 ", and "post-60") was calculated. A non-parametric Levene's test was used to verify the equality of variances in the samples (homogeneity of variance). Then, an independent samples t-test was used to compare the mean $\mathrm{z}$-scores between groups.

Statistical significance was defined as $\mathrm{p}<0.05$. The statistical analysis was generated using SPSS (New York, USA), version 20, for windows.

\section{Results}

The characteristics of the participants are shown in Table 1. The four experimental groups were not different regarding age, weight, height, body mass index, waist circumference, and systolic/diastolic resting BP.

Table 2 presents the absolute HRV changes in the different experimental groups. Considering the CG, a significant increase in SDNN [80\% (post-60)] and pNN50 [150\% (post-30) and 200\% (post-60)] were identified when compared with the "pre". In the EG, significant increases in LF $[27 \%$ (post-30) and $23 \%$ (post-60)] and LF/HF [141\% (post-30) and $65 \%$ (post-60)] were identified ( $v$ s. "pre"). On the other hand, the EG showed a significant decrease in $\mathrm{HF}[-45 \%$ (post-30) and $-37 \%$ (post-60)]. No significant differences were found between experimental groups.

Table 3 presents the effect sizes from the paired t-test (rest vs. post-30 and post-60) for each group. Considering the CG, increases with a large effect were observed in SDNN (post-60), RMSSD (post30 and post-60), and pNN50 (post-30 and post60 ). On the other hand, the EG presented increases with a large effect for LF (post-30 and post-60) and LF/HF (post-30 and post-60). Finally, a reduction 
Table 1. Characteristics of participants

\begin{tabular}{|l|c|c|c|c|c|c|}
\hline \multirow{2}{*}{} & \multicolumn{2}{|c|}{ CG } & \multicolumn{2}{c|}{ EG } & \multirow{2}{*}{ t } & P \\
\cline { 2 - 6 } & Mean & SD & Mean & SD & & \multirow{2}{*}{0.195} \\
\hline Age [years] & 62.3 & 18.7 & 52.0 & 15.3 & 1.347 & 0.744 \\
\hline Weight $[\mathrm{kg}]$ & 77.2 & 16.5 & 79.7 & 17.1 & -0.332 & 0.315 \\
\hline Height $[\mathrm{m}]$ & 1.65 & 0.11 & 1.61 & 0.08 & 1.033 & 0.261 \\
\hline BMl $\left[\mathrm{kg} / \mathrm{m}^{2}\right]$ & 27.9 & 4.3 & 30.8 & 6.5 & -1.161 & 0.958 \\
\hline WC $[\mathrm{cm}]$ & 98.2 & 9.9 & 98.5 & 14.9 & -0.053 & 0.648 \\
\hline SBP $[\mathrm{mm} \mathrm{Hg}]$ & 140 & 19 & 137 & 12 & 0.465 & 0.433 \\
\hline DBP $[\mathrm{mm} \mathrm{Hg}]$ & 82 & 5 & 86 & 11 & -0.809 & 0 \\
\hline
\end{tabular}

CG — control-group; EG — exercise-group; SD — standard deviation; BMI — body mass index; WC — waist circumference; SBP — systolic blood pressure; DBP — diastolic blood pressure

Table 2. Heart rate variability component variations

\begin{tabular}{|l|c|c|c|c|c|c|c|c|c|c|c|c|}
\hline & \multicolumn{9}{|c|}{ CG } & \multicolumn{6}{c|}{ EG } \\
\hline & \multicolumn{2}{|c|}{ Pre } & \multicolumn{2}{c|}{ Post-30 } & \multicolumn{2}{c|}{ Post-60 } & \multicolumn{2}{c|}{ Pre } & \multicolumn{2}{c|}{ Post-30 } & \multicolumn{2}{c|}{ Post-60 } \\
\hline & Mean & SD & Mean & SD & Mean & SD & Mean & SD & Mean & SD & Mean & SD \\
\hline SDNN [ms] & 54 & 26 & 70 & 58 & 97 & $77^{*}$ & 72 & 24 & 97 & 37 & 61 & $19^{+}$ \\
\hline RMSSD [ms] & 24 & 9 & 30 & 9 & 41 & 26 & 34 & 9 & 30 & 33 & 54 & 64 \\
\hline pNN50 (\%) & 4 & 4 & 10 & $10^{*}$ & 12 & $11^{*}$ & 17 & 16 & 11 & 18 & 14 & 15 \\
\hline LFnu & 69 & 19 & 70 & 10 & 62 & 17 & 62 & 19 & 79 & $12^{*}$ & 76 & $9^{*}$ \\
\hline HFnu & 31 & 19 & 29 & 11 & 38 & 17 & 38 & 19 & 21 & $12^{*}$ & 24 & $9^{*}$ \\
\hline LF/HF & 2.8 & 1.8 & 2.3 & 0.8 & 1.6 & 1.1 & 1.7 & 1.1 & 4.1 & $2.5^{*}$ & 2.8 & $0.9^{*}$ \\
\hline
\end{tabular}

CG — control-group; EG — exercise-group; SD — standard deviation; SDNN — standard deviation of the NN intervals; RMSSD — the square root of the mean of the sum of the squares of differences between adjacent NN intervals), pNN50 - NN50 count divided by the total number of all NN intervals; LF — low frequencies; HF — high frequencies; ${ }^{*}$ significantly different from pre-intervention (p $<0.05$ ); ${ }^{\dagger}$ significantly different from post-30 ( $p<0.05) ; "$ significantly different from control $(\mathrm{p}<0.05)$

Table 3. Effect size for paired t-test [vs. pre $(d=$ mean/SD)]

\begin{tabular}{|l|c|c|c|c|c|c|c|c|}
\hline & \multicolumn{4}{|c|}{ CG } & \multicolumn{4}{c|}{ EG } \\
\hline & \multicolumn{2}{|c|}{ Post-30 } & \multicolumn{2}{c|}{ Post-60 } & \multicolumn{2}{c|}{ Post-30 } & \multicolumn{2}{c|}{ Post-60 } \\
\hline & ES & $\mathbf{p}$ & ES & $\mathbf{p}$ & ES & $\mathbf{p}$ & ES & $\mathbf{p}$ \\
\hline SDNN [ms] & 0.4 & 0.243 & 0.8 & 0.032 & 0.8 & 0.052 & -0.7 & 0.132 \\
\hline RMSSD [ms] & 0.8 & 0.049 & 0.8 & 0.067 & -0.1 & 0.816 & 0.3 & 0.442 \\
\hline pNN50 (\%) & 0.9 & 0.026 & 1.1 & 0.008 & -0.6 & 0.072 & -0.2 & 0.519 \\
\hline LFnu & 0.1 & 0.829 & -0.3 & 0.394 & 1.0 & 0.014 & 1.0 & 0.013 \\
\hline HFnu & -0.1 & 0.756 & 0.3 & 0.394 & -1.0 & 0.014 & -1.0 & 0.013 \\
\hline LF/HF & -0.4 & 0.264 & -0.5 & 0.163 & 0.8 & 0.028 & 1.1 & 0.018 \\
\hline
\end{tabular}

CG - control-group; EG — exercise-group; SD — standard deviation; SDNN — standard deviation of the NN intervals; RMSSD — the square root of the mean of the sum of the squares of differences between adjacent NN intervals), pNN50 - NN50 count divided by the total number of all NN intervals; LF — low frequencies; HF — high frequencies

with a large effect was found for HF (post-30 and post-60).

The pooled (CG, and EG) z-scores for time (panel A) and frequency (panel B) HRV domains are presented in Figures 2 (pre), 3 (post-30), and 4 (post-60). No significant differences were found in "pre" and "post-60" for any time or frequency components.

\section{Discussion}

The purpose of this study was to analyze the postaerobic-exercise autonomic responses in hypertensive subjects. Our results showed that there was a considerable reduction in post-aerobic-exercise parasympathetic activity and an increase in sympathetic activity. 
A

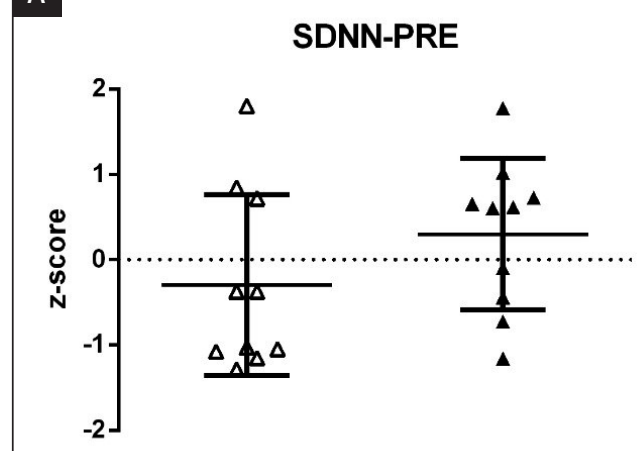

RMSSD-PRE

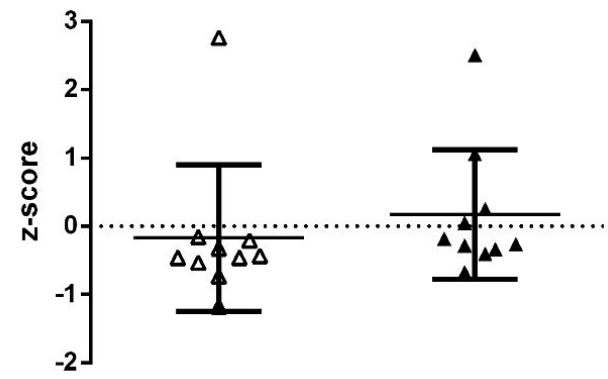

PNN50-PRE

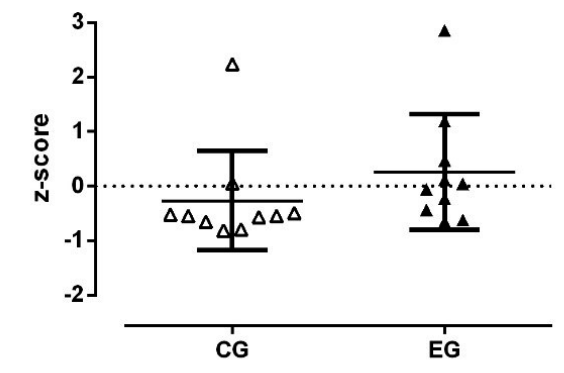

B

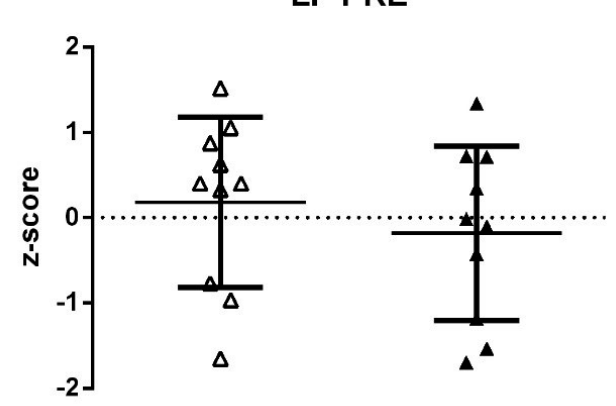

HF-PRE

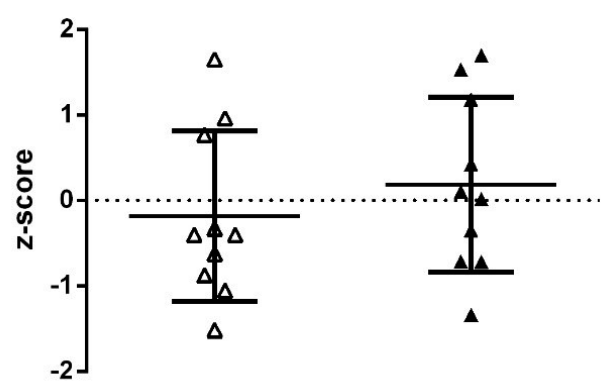

LF/HF-PRE

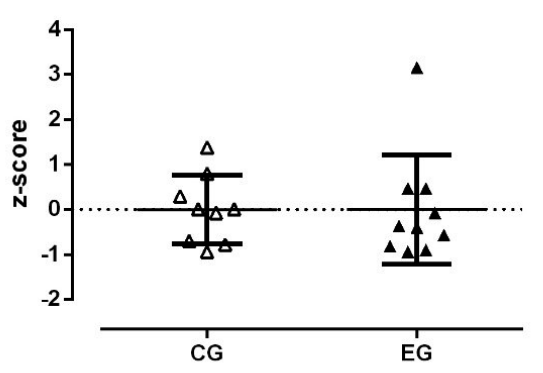

Figure 2. Pooled z-score comparisons at Pre

The present study demonstrated that hypertensives present an autonomic profile related to cardiovascular disabilities. It is important to consider that monitoring HRV responses to an "exercise challenge test" may provide useful insight into autonomic stress reactivity. This is consistent with the "reactivity hypothesis" [16], which proposes that cardiovascular responses to a stressor may be predictive of certain diseases [17].

Although this relationship between hypertension and an unfavorable HRV profile may exist, indica- tors of adiposity are correlated with cardiac autonomic modulation in individuals with excess body mass, since higher levels of adipose mass are related to major metabolic and inflammatory modifications that can impair autonomic cardiac modulation [18]. For this reason, it is important to consider that in the present study hypertensives presented excess body mass. On the other hand, a recent study showed that higher cardiorespiratory fitness and lower adiposity are associated with higher HRV. Notably, although 
A

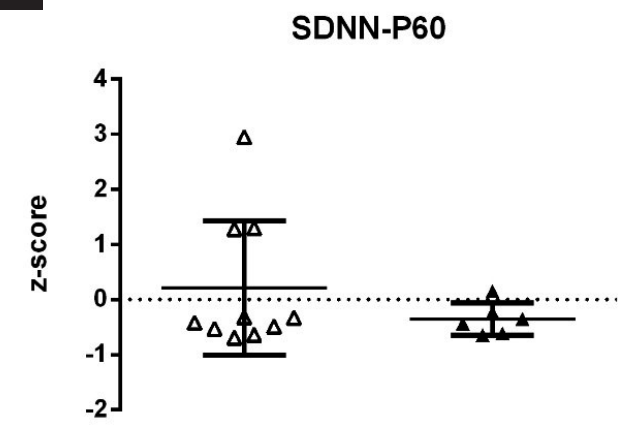

RMSSD-P60

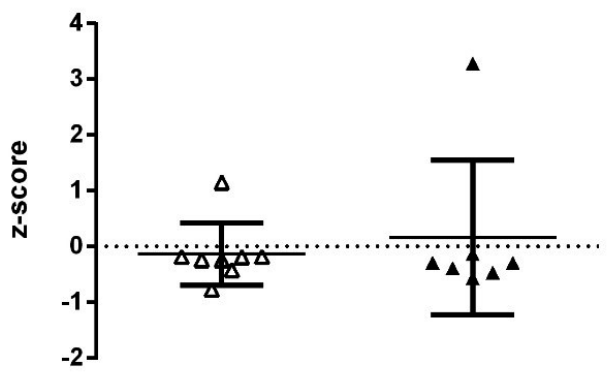

pNN50-P60

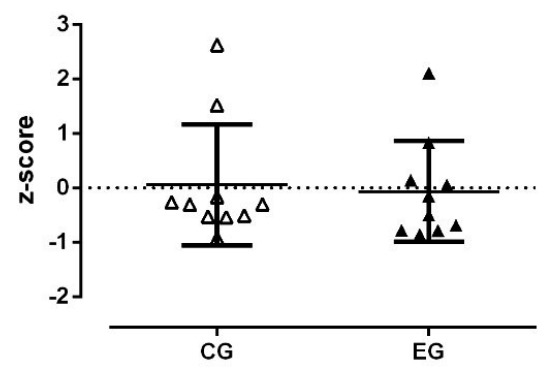

B

\section{LF-P60}

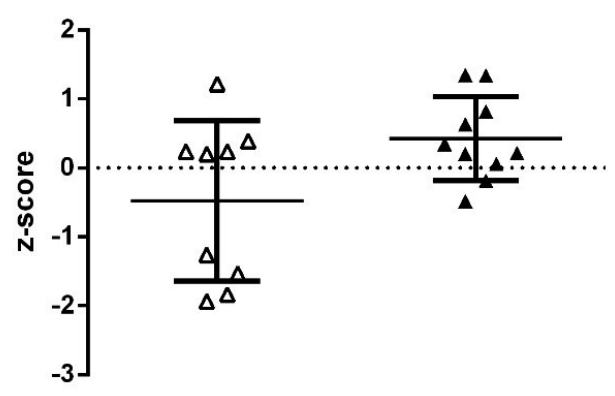

HF-P60

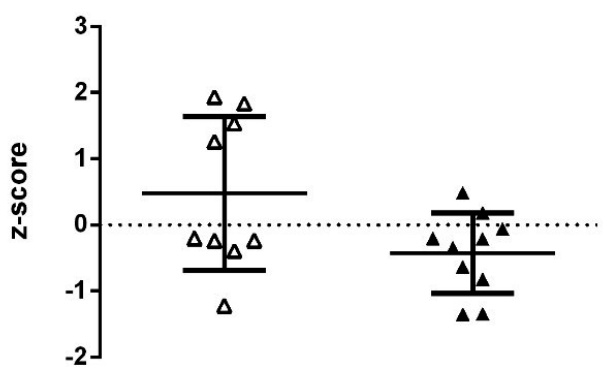

LF/HF-P60

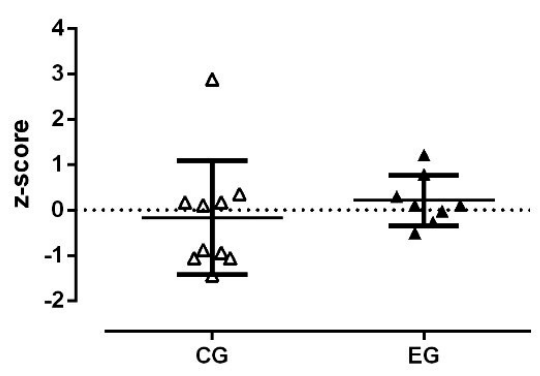

Figure 3. Pooled z-score comparisons at P30

the cardiorespiratory fitness associations remained significant after adjusting for adiposity, the adiposity associations were no longer significant after adjusting for cardiorespiratory fitness, suggesting that cardiorespiratory fitness is a stronger determinant of HRV [19].

The EG presented increases (large effect) for $\mathrm{LF}$ and LF/HF. It is worth highlighting that sympathetic activity is a key contributor to LF and sympathetic and parasympathetic activity/effects operate reciprocally with linear interactions [20]. $\mathrm{LF} / \mathrm{HF}$ is often employed as a measure of "sympathovagal balance," where supposedly an increase indicates "sympathetic dominance" and a decrease indicates "parasympathetic dominance" [20]. It is well documented that hypertensive elderly patients present absolute decreased HRV and decreased parasympathetic modulation when compared to normotensive individuals [21]. Additionally, independently of blood pressure status, the majority 


\section{A}

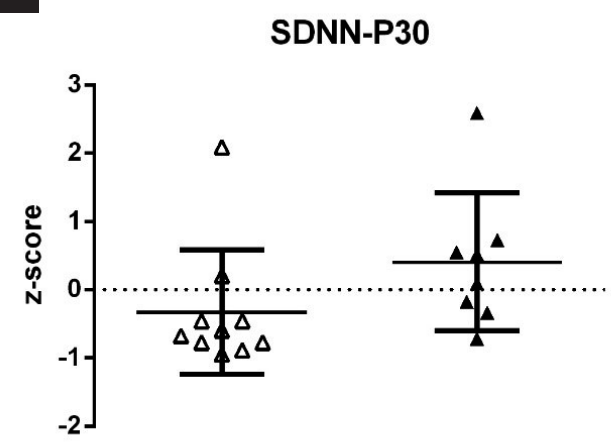

RMSSD-P30

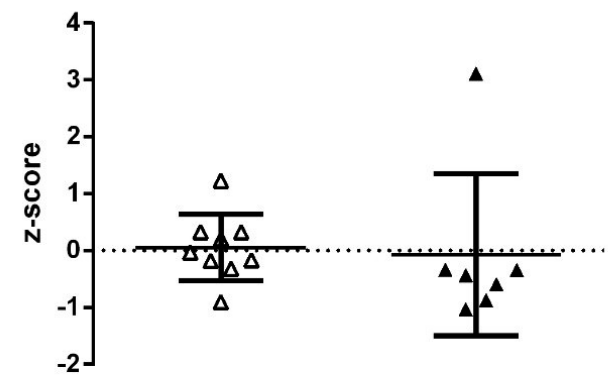

pNN50-P30

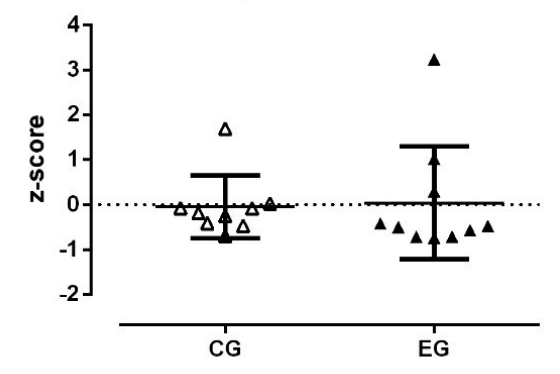

\section{B}

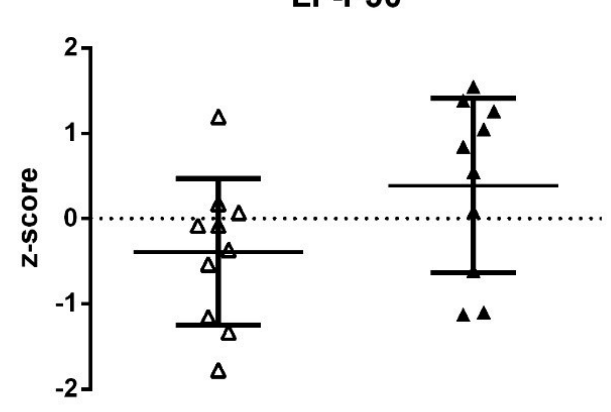

HF-P30

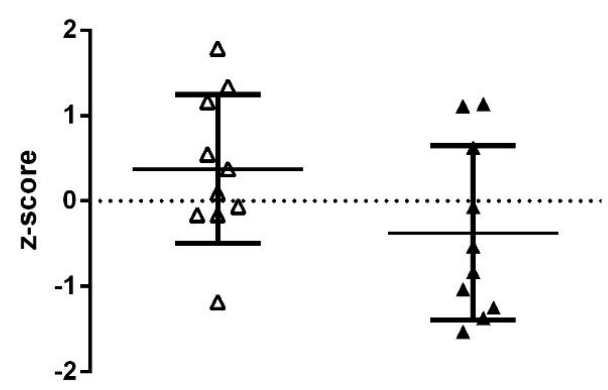

LF/HF-P30

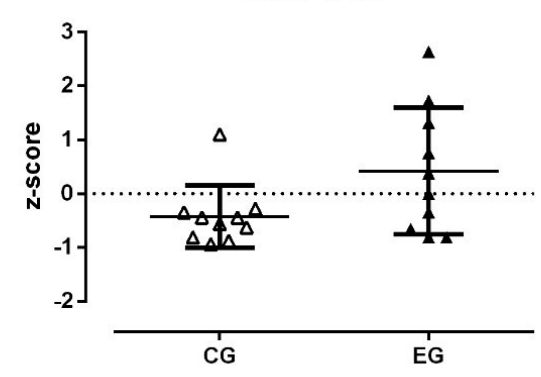

Figure 4. Pooled z-score comparisons at P60

of HRV measures are substantially reduced during exercise [20]. HRV indices associated with the cardiac parasympathetic activity (e.g., RMSSD and $\mathrm{HF}$ ) usually reach a near-zero minimum at moderate intensity (possibly associated with the first ventilation/lactate threshold) [20].The autonomic nervous system (ANS) has been implicated in hypertension with elevated sympathetic nervous system (SNS) activity and decreased parasympathetic nervous system (PNS) activity associated with the etiology, course, progression, and consequences of hypertension [22]. Therefore, we standardized the scores. No significant differences were found for CG and EG, indicating that a single bout of aerobic exercise is not able to quickly improve the cardiac autonomic regulation. This fact is corroborated by other researchers [23], who state that hypertensives present greater autonomic dysfunction and slower recovery, making them more susceptible to exercise intolerance. 
Despite all methodological care, some aspects should be considered. This was an acute experiment conducted to analyze the post-aerobic exercise autonomic responses in hypertensives. However, it should not be assumed that underlying mechanisms for chronic changes in HRV are identical to those of acute responses [24]. Furthermore, interpretation of HRV as reflecting certain aspects of cardiac autonomic activity is complicated by the fact that rather than being a direct measure of autonomic nerve activity, HRV quantifies the modulation of the endorgan response, i.e., the heart [20].

\section{Conclusions}

These results suggest that there is a considerable reduction in post-aerobic-exercise parasympathetic activity and an increase in sympathetic activity for hypertensives. Therefore, a single bout of aerobic exercise is not able to quickly improve cardiac autonomic regulation.

\section{Compliance with ethical standards and funding}

The authors declare no conflict of interest and did not receive any funding for this project.

\section{Conflict of interests}

None to be declared by authors.

\section{Acknowledgment}

Fundação Nacional de Desenvolvimento do Ensino Superior Particular - FUNADESP.

\section{References}

1. Heart rate variability: standards of measurement, physiological interpretation and clinical use. Task Force of the European Society of Cardiology and the North American Society of Pacing and Electrophysiology. Circulation. 1996; 93(5): 1043-1065, indexed in Pubmed: 8598068.

2. Lees Ty, Shad-Kaneez F, Simpson A, et al. Heart Rate Variability as a Biomarker for Predicting Stroke, Post-stroke Complications and Functionality. Biomarker Insights. 2018; 13: 117727191878693, doi: 10.1177/1177271918786931, indexed in Pubmed: 30038486.

3. Sen J, McGill D. Fractal analysis of heart rate variability as a predictor of mortality: A systematic review and meta-analysis. Chaos. 2018; 28(7): 072101, doi: 10.1063/1.5038818, indexed in Pubmed: 30070502.

4. Kung HC, Xu J. Hypertension-related Mortality in the United States, 2000-2013. NCHS Data Brief. 2015; 193: 1-8, indexed in Pubmed: 25932893.

5. Goit R, Ansari A. Reduced parasympathetic tone in newly diagnosed essential hypertension. Indian Heart J. 2016; 68(2): 153-157, doi: 10.1016/j.ihj.2015.08.003, indexed in Pubmed: 27133323.
6. Stein P, Ehsani A, Domitrovich P, et al. Effect of exercise training on heart rate variability in healthy older adults. Am Heart J. 1999; 138(3 (Pt 1)): 567-576, doi: 10.1016/s0002-8703(99)70162-6, indexed in Pubmed: 10467210.

7. Plews D, Laursen P, Stanley J, et al. Training Adaptation and Heart Rate Variability in Elite Endurance Athletes: Opening the Door to Effective Monitoring. Sports Med. 2013; 43(9): 773-781, doi: 10.1007/s40279-013-0071-8, indexed in Pubmed: 23852425.

8. Heffernan K, Fahs $\mathrm{C}$, Shinsako K, et al. Heart rate recovery and heart rate complexity following resistance exercise training and detraining in young men. Am J Physiol Heart Circ Physiol. 2007; 293(5): H3180-H3186, doi: 10.1152/ajpheart.00648.2007, indexed in Pubmed: 17890428.

9. Bocalini D, Bergamin M, Evangelista A, et al. Post-exercise hypotension and heart rate variability response after water- and landergometry exercise in hypertensive patients. PLOS ONE. 2017; 12(6): e0180216, doi: 10.1371/journal.pone.0180216, indexed in Pubmed: 28658266.

10. Malliani A. Heart rate variability: from bench to bedside. Eur J Int Med. 2005; 16(1): 12-20, doi: 10.1016/j.ejim.2004.06.016, indexed in Pubmed: 15733815.

11. Gordon CC, Chumlea WC. Stature, recumbent length, and weight. In: Lohman TG, Roche AF, Martorell R. ed. Anthropometric Standardization Reference Manual. Human Kinetics Books, Champaign 1988: 3-8.

12. Quintana D, Heathers J, Kemp A. On the validity of using the Polar RS800 heart rate monitor for heart rate variability research. Eur J Appl Phys. 2012; 112(12): 4179-4180, doi: 10.1007/s00421-0122453-2, indexed in Pubmed: 22790488.

13. Coleman A, Freeman P, Steel S, et al. Validation of the Omron MX3 Plus oscillometric blood pressure monitoring device according to the European Society of Hypertension international protocol. Blood Pres Monit. 2005; 10(3): 165-168, doi: 10.1097/00126097200506000-00009, indexed in Pubmed: 15923819.

14. Pickering T, Hall J, Appel L, et al. Recommendations for Blood Pressure Measurement in Humans and Experimental Animals. Part 1: blood pressure measurement in humans: a statement for professionals from the Subcommittee of Professional and Public Education of the American Heart Association Council on High Blood Pressure Research. Hypertension. 2005; 45(1): 142-161, doi: 10.1161/01. hyp.0000150859.47929.8e, indexed in Pubmed: 15611362.

15. Queiroz A, Sousa J, Cavalli A, et al. Post-resistance exercise hemodynamic and autonomic responses: Comparison between normotensive and hypertensive men. Scand J Med Sci Sports. 2014; 25(4): 486-494, doi: 10.1111/sms.12280, indexed in Pubmed: 24981630.

16. Heponiemi T, Elovainio M, Pulkki L, et al. Cardiac autonomic reactivity and recovery in predicting carotid atherosclerosis: The cardiovascular risk in young finns study. Health Psych. 2007; 26(1): 13-21, doi: 10.1037/0278-6133.26.1.13, indexed in Pubmed: 17209693.

17. Treiber F, Kamarck T, Schneiderman N, et al. Cardiovascular Reactivity and Development of Preclinical and Clinical Disease States. Psychosom Med. 2003; 65(1): 46-62, doi: 10.1097/00006842200301000-00007, indexed in Pubmed: 12554815.

18. Araújo J, Queiroz M, Dias A, et al. Isolated Obesity Is Not Enough to Impair Cardiac Autonomic Modulation in Metabolically Healthy Men. Res Q Exerc Sport. 2019; 90(1): 14-23, doi: 10.1080/0270 1367.2018.1549357.

19. Chen LY, Zmora R, Duval S, et al. Cardiorespiratory Fitness, Adiposity, and Heart Rate Variability: The Coronary Artery Risk Development in Young Adults Study. Med Sci Sports Exerc. 2019; 51(3): 509-514, doi: 10.1249/MSS.0000000000001796, indexed in Pubmed: 30277902.

20. Michael S, Graham K, Davis G. Cardiac Autonomic Responses during Exercise and Post-exercise Recovery Using Heart Rate Variability and Systolic Time Intervals - A Review. Front Physiol. 2017; 8(301), doi: 10.3389/fphys.2017.00301, indexed in Pubmed: 28611675. 
21. Andrade Pde, Amaral Jdo, Paiva L, et al. Reduction of heart rate variability in hypertensive elderly. Blood Press. 2017; 26(6): 350-358, doi: 10.1080/08037051.2017.1354285, indexed in Pubmed: 28738697.

22. Brook R, Julius S. Autonomic imbalance, hypertension, and cardiovascular risk. Am J Hypertens. 2000; 13(6): S112-S122, doi: 10.1016/s0895-7061(00)00228-4, indexed in Pubmed: 10921530 .
23. Verma S, Bhati P, Ahmad I, et al. Co-Existence of hypertension worsens post-exercise cardiac autonomic recovery in type 2 diabetes. Indian Heart J. 2018; 70(Suppl 3): S82-S89, doi: 10.1016/j. ihj.2018.06.007, indexed in Pubmed: 30595327.

24. Mourot L, Bouhaddi M, Tordi N, et al. Short-and long-term effects of a single bout of exercise on heart rate variability: comparison between constant and interval training exercises. Eur J Appl Physiol. 2004; 92(4-5), doi: 10.1007/s00421-004-1119-0, indexed in Pubmed: 15461995. 